\title{
Response to the letter to the editor: Venous oxygen saturation is reduced and variable in central retinal vein occlusion
}

\author{
Thorunn Scheving Eliasdottir • David Bragason • \\ Sveinn Hakon Hardarson • Gudrun Kristjansdottir • \\ Einar Stefánsson
}

Received: 15 December 2014 / Accepted: 17 December 2014 / Published online: 8 January 2015

(C) Springer-Verlag Berlin Heidelberg 2015

\begin{abstract}
Dear editor;
We want to thank Yolcu et al. for their insightful letter about our study. We fully agree with their opinion on pertinence for oximetric results of central retinal vein occlusion (CRVO) eyes with and without macular edema or retinal ischemia to be compared with each other. We also agree that its results can be compared with fluorescein angiography and optical coherence tomography findings in different sectors of the retinal fundus. This is important in order to explore the clinical utility of the oximeter.
\end{abstract}

T. S. Eliasdottir · S. H. Hardarson · G. Kristjansdottir • E. Stefánsson University of Iceland, Reykjavik, Iceland

T. S. Eliasdottir $(\bowtie) \cdot D$. Bragason • S. H. Hardarson • E. Stefánsson Department of Ophthalmology, University of Iceland, Landspitali The National University Hospital of Iceland, Eiriksgata 37, 101 Reykjavík, Iceland

e-mail: tse@hi.is

T. S. Eliasdottir Department of Anesthesiology, Landspítali - University Hospital, Reykjavik, Iceland
Our study [1] demonstrates variable retinal hypoxia in CRVO eyes that in general seems to get better with time, treatment and improving clinical symptoms.

Our preliminary findings suggest a correlation between retinal oximeter measurements and clinical signs and symptoms. Hypoxia measurements in retinal venules were consistent with capillary nonperfusion on fluorescein angiography [1].

We agree that assessing patients by optical coherence tomography and fluorescein angiography and comparing with retinal oximeter measurements will provide valuable information for the pathogenesis and management of CRVO. We have started a multicenter study in order to answer the aforementioned questions and pursue the clinical utility of retinal oximetry in CRVO.

Conflict of interest Einar Stefánsson and Sveinn Hakon Hardarson have financial interest in the retinal oximeter used in the study.

\section{References}

1. Eliasdottir TS, Bragason D, Hardarson SH, Kristjansdottir G, Stefansson E (2014) Venous oxygen saturation is reduced and variable in central retinal vein occlusion. Graefes Arch Clin Exp Ophthalmol. doi:10.1007/s00417-014-2849-2 